\title{
ONESC: A database of orthographic neighbors for Spanish read by children
}

\author{
Jesús A. Martínez Martín and M. Emma Garcia Pérez \\ Universidad Pontificia de Salamanca, Salamanca, Spain
}

In this article, we present a database of orthographic neighbors for words that Spanish children read during elementary education. The reference dictionary for lexical entries and frequencies (which had its origin in Martinez \& García, 2004) comprises approximately 100,000 words and is the result of accumulating the words read by a sample of children from first to sixth grades. Using the criterion for orthographic neighbors described by Coltheart, Davelaar, Jonasson, and Besner (1977), we present basic statistics related to neighborhood size as a function of the positions of divergent letters, the cumulative frequency of the neighbors, and the numbers of neighbors of higher, lower, and equal frequency. We also attempt to illustrate and unravel the nature of the relationships among the variables neighborhood size, length, and frequency in the distribution of neighbors. The database described in this article is available at www.psychonomic.org/archive.

In this article, we present a database of orthographic neighbors based on the words obtained from a dictionary compiled for children. The interest of this work lies in the fact that, in Spanish, we have no databases of orthographic neighbors based on dictionaries of printed frequency for children. For this reason, we present a database of orthographic neighbors that has the special characteristic of being compiled from the frequency of lexical entries obtained from readings carried out by a population of children 6 to 12 years of age (Martinez \& Garcia, 2004).

We know that in psycholinguistic studies, specifically in the context of word recognition, normative databases of lexical and sublexical variables are necessary in order to verify the roles the different variables play. Taking into account the particular characteristics of different languages, a good number of indexes of normative studies aimed at facilitating the necessary selection of stimuli in psycholinguistic research have proliferated (for a review of normative studies and databases available in Spanish, see Pérez, Campoy, \& Navalón, 2001).

The orthographic neighborhood, together with word frequency, length, regularity, and degree of abstraction, is one of the variables known to have an influence on lexical recognition. It was defined by Coltheart, Davelaar, Jonasson, and Besner (1977), who considered the neighbors of a word to be all words having the same length, maintaining the same order of letters, and differing by only one letter. This is the case, for example, of the Spanish words misa, musa, meta, and besa, which are all orthographic neighbors of the word mesa.

According to parallel activation models (McClelland \& Rumelhart, 1981) and the search/verification model (Forster, 1976) of word recognition, the effect of neigh- borhood size or density derives from the fact that orthographically similar words compete for lexical recognition, thus increasing reaction times (Grainger \& Segui, 1990). However, the results of different studies have not always converged. These inconsistencies seem to depend on the interaction between neighborhood size and a series of variables, such as the frequency of the neighbors, the presence among them of a high-frequency neighbor, the type of task considered (naming vs. lexical decision), the characteristics of the stimuli selected in the task, and even the languages in which their effect is tested. The panorama is not easy to explain. According to the metaanalysis of Andrews (1997), a relatively solid facilitating effect seems to arise from neighborhood size. In $77 \%$ of the experimental situations ( 33 out of 43), neighborhood size had a facilitating effect on the task. Thus, for example, Sears, Hino, and Lupker (1995) found that, for lowfrequency words, having a large neighborhood facilitates processing for both naming and lexical decision. Thus, words such as mite and rash (of low frequency and with large numbers of neighbors) would be processed more quickly than words such as clue and epic (which are also of low frequency but have small neighborhoods). Of the 10 experiments in which this facilitating effect was not found, 3 showed an inhibiting effect and 7 a null effect. However, the effects of neighbor frequency are apparently less solid. The most tangible result is a certain inhibiting effect generated by high-frequency neighbors (found in $54 \%$ of the studies). Thus, for example, the work of Carreiras, Perea, and Grainger (1997) describes an inhibiting effect for neighborhood frequency. Hence, Spanish words with high-frequency neighbors (e.g., vapor, "steam"), would be processed more slowly than words with low- 
frequency neighbors (e.g., culto, "cult," "cultivated"). Accommodating or explaining this result (i.e., the inhibiting effect of high-frequency neighbors) in word recognition models does not seem to be very complicated. The activation generated by these words would interfere with the processing of neighbors of lower frequency. Nevertheless, the facilitating effect of neighborhood size seems to be more difficult to fit to the models. More studies are undoubtedly needed to clearly determine the conditions or variables that generate facilitating or inhibiting effects in word recognition. A necessary, although not sufficient, first step is to have databases of suitable neighbors in the different languages and for different populations.

The study of the effect of this variable has aroused great interest and brought about the proliferation of databases of orthographic neighborhoods in different languages, just as has occurred with other variables of unquestionable importance in word recognition (e.g., lexical frequencyAlameda \& Cuetos, 1995; Baayen, Piepenbrock, \& Gulikers, 1995; Kučera \& Francis, 1967; Martínez \& García, 2004; Thorndike \& Lorge, 1944). Thus, we find databases of orthographic neighbors in English for the adult population, such as MRC (Coltheart, 1981), MCWord (Medler \& Binder, 2005), WordMine (Buchanan \& Westbury, 2000), and, more recently, N-Watch (Davis, 2005), which are based on the prevailing dictionaries of lexical frequency of the time, such as CELEX (Baayen et al., 1995), or, in some cases, on Web pages. There is also a version of this database in Basque: E-Hitz by Perea et al. (2006). In Italian, the works of Burani, Barca, and Arduino (2001; Barca, Burani, \& Arduino, 2002) are worthy of mention. We can also highlight Balota et al.'s (2007) recent publication of the broad database in English, which provides normative data about orthographic neighborhood, among other statistics. In Spanish, we have the studies by Alameda (1996), Alameda and Cuetos (1996, 2001), Perea (1993), and Pérez, Alameda, and Cuetos (2003). Recently, a Spanish version of Davis's N-Watch program was published (Davis \& Perea, 2005). It applies Davis's wordsearch to the lexical entries of the LEXESP (Sebastian-Gallés, Martí, Carreiras, \& Cuetos, 2000).

In general, orthographic neighborhood density is obtained by means of computer procedures applied to the database of words contained in the lexical frequency dictionaries available in the different languages. It must be said that, for the most part, these lexical frequency dictionaries refer to the adult population. Their frequencies are estimations that reflect the number of times the average adult is exposed to the words of the dictionary during his or her reading. Thus, both the number of orthographic neighbors and their frequencies are contextualized in the adult population. Furthermore, considering that the stimuli obtained for adult samples probably will not serve for a child population, it is necessary to have available orthographic neighborhood data from samples obtained from children's reading. In a preliminary study, Martínez and García (2007) compared the results of Alameda and Cuetos's (1995) dictionary based on the adult population with those of Martínez and Garcia's (2004) frequency dictionary for the child population. Martínez and García (2007) yielded data that justify the use of specific dictionaries for the child population in the selection of stimuli. The data indicate that the words to which children have been exposed do not necessarily form part of the word set to which adults have been exposed. Specifically, $44.75 \%$ of the words in the cumulative lexical frequency dictionary for the six grades of elementary education do not appear in the adult dictionary. Likewise, $31.43 \%$ of the words in the adult dictionary are specific to that population and do not appear in the children's dictionary. ${ }^{1}$ Both dictionaries share exactly 55,767 words, making up $55.25 \%$ of the children's dictionary and $68.57 \%$ of the adult dictionary. Moreover, the frequencies of some of the words shared by both dictionaries are highly divergent. Words such as vida, mujer, hombre, muerte, sociedad, guerra, amor, and ciencia ("life, "woman," "man," "death," "society," "war," "love," and "science," respectively), of frequent use among adults, are used much less frequently by children, whereas words such as casa, madre, señor, padre, agua, cuaderno, abuelo, and cabeza ("house," "mother," "man," "father," "water," "notebook," "grandfather," and "head") are more frequent within the reading vocabulary of children and much less so in that of adults. Thus, if we consider that word frequency dictionaries are different for adults and for children, we can pose that, necessarily, databases of orthographic neighbors should be obtained with reference to both the adult and the child populations.

In response to this need, in the last 5 years orthographic neighbor databases have appeared in both English (e.g., the Children's Printed Word Database-Masterson, Stuart, Dixon, Lovejoy, \& Lovejoy, 2003) and French (NOVLEX - Lambert \& Chesnet, 2001; MANULEXLété, Sprenger-Charolles, \& Colé, 2004).

Aware of the importance of meeting this need in Spanish, we present below an orthographic neighbor database for the child population. More specifically, this database has been developed from the written words to which children 6-12 years of age are exposed during elementary education. We feel that making available this methodological tool specifically for the child population will be of great use to psycholinguistic and cognitive psychology researchers interested in lexical recognition processes. Concretely, it will allow them to make a careful selection of stimuli for experiments with the child population, controlling neighborhood size and the frequency of the words comprising it, in addition to classic variables such as word frequency and length.

\section{METHOD}

\section{Reference Corpus: Word Frequency Dictionary}

To compile the database of orthographic neighbors, we took as a basis Martínez and Garcia's (2004) dictionary of frequencies for written language in children 6-12 years of age. In this dictionary, we attempted to make a quasi-absolute database of the words that a small group of children encountered in their reading. Eight children were selected from each of the elementary grades, and from each child a good percentage of what she or he had read during the year was incorporated into the dictionary. ${ }^{2}$

We thus have a dictionary for each of the six grades. Each of them is made up of the words read by the corresponding group of 8 
children, the frequency of each word being the average number of times it appears for this group of children. Taking into account that the children in each grade had been exposed to words form previous grades, we also compiled five cumulative dictionaries (Grades $1+2$, Grades $1+2+3$, Grades $1+2+3+4$, Grades $1+2+3+$ $4+5$, and Grades $1+2+3+4+5+6$ ). The database of orthographic neighbors that we present here is based on the cumulative dictionary of the six grades and contains 100,944 words. The general inclusion criterion for word entries was that of the word-form part of the Diccionario de la Lengua Espanola (Dictionary of the Spanish Language-Real Academia Española de la Lengua, 1998). We refer the reader to Martinez and García (2004) for more details about the inclusion/exclusion criteria of the different words.

\section{Procedure for Obtaining Neighbors and the \\ Parameters Analyzed}

The database of neighbors we present here is based on the concept of orthographic neighbors as defined by Coltheart et al. (1977), mentioned above. We thus consider the neighbors of a given word to be those words with the same word length (i.e., number of letters) that differ by only one letter and preserve the order of the rest of the letters. This analysis was carried out with all the words in the dictionary described above that were capable of having neighbors. In our case, these were words with 2-18 letters.

For each word, in addition to neighborhood size (i.e., number of neighbors), we calculated the cumulative frequency of its group of neighbors; the numbers of neighbors of frequency higher than, lower than, and equal to that of the word itself; and the position occupied by the divergent letter of each neighbor. Taking into account that our data on the frequency of each word come from averaging and, therefore, have decimals, we considered as words of equal frequency those whose values did not oscillate by more than 1 integer in absolute values.

\section{RESULTS}

The results are presented in the file ONESC.xls (see Archived Materials section) with the words organized by word length, beginning with 2 letters and ending with 18 . On each page and on each tab of the file, the first column contains the different words ordered from higher to lower frequency. In the top row, the following descriptors are presented:

Word: Stimulus or dictionary entry

Word Freq.: frequency of the word in the reference dictionary (cumulative from first grade to sixth grade)

No. letters: number of letters

No. neighbors: number of neighbors, or neighborhood size

Cum. Freq. Neigh.: cumulative frequency of the neighbors of each word

$\mathrm{N} n$ higher: number of neighbors of higher frequency

$\mathrm{N} n$ equal: number of neighbors of equal frequency

$\mathrm{N} n$ lower: number of neighbors of lower frequency

1: number of neighbors that diverge in the first letter

2: number of neighbors that diverge in the second letter

3:... . etc.

\section{Data Analysis}

In this section, we present a descriptive analysis of the fundamental statistics of the reference dictionary and the database of neighbors. First, we comment on the data relating to the reference dictionary-that is, the number of words and their frequencies in relation to length. We then present the information relating to the size and characteristics of the neighborhood.

Length, number, and frequency of words in the reference dictionary. The distribution of the number of words for each length segment (measured as the number of letters) fits the normal curve, as can be seen in Table 1. The mean is located at $8.8(S D=2.3)$. This means that the words with the greatest diversity (type frequency) in the books children read in elementary education are those having around nine letters. We know that type frequency is different from the concept of token frequency, defined as the number of times the child encounters the word when reading. In fact, Table 1 shows that the words with the highest frequencies of appearance are the shortest, with frequency progressively decreasing with increasing word length. Although the shortest words are on average the most frequent, the variability of these frequencies is very high.

Characteristics of the neighborhood. In this section, we analyze the characteristics of the neighborhood considering the number of words with one or more neighbors, the relationship between neighborhood size and word length, and the relationship between neighborhood size and frequency.

Words with neighbors. If we consider the number of words that have, in each length segment, a neighbor (or neighbors) with frequency higher than, lower than, or equal to their own respective frequencies, we find quite a well-defined distribution. The graph in Figure 1A shows that these distributions of the number of words having neighbors in each length segment fit a normal curve. In absolute terms, the largest number of words with neighbors in the four distributions of Figure $1 \mathrm{~A}$ is grouped around words of 7 to 10 letters. This is not surprising, since, as we saw in Table 1, words in these groups are considerably more numerous and, therefore, more of them will have neighbors. However, when we transform these numbers

Table 1

Characteristics of the Words in the Reference Dictionary (Cumulative Words from Grades 1-6)

\begin{tabular}{crrr}
\hline \multirow{2}{*}{$\begin{array}{c}\text { No. } \\
\text { Letters }\end{array}$} & No. & \multicolumn{2}{c}{ Frequency* } \\
\cline { 3 - 4 } Words & 93 & \multicolumn{1}{c}{$M$} & \multicolumn{1}{c}{$S D$} \\
\hline 2 & 356 & $1,117.95$ & $5,714.72$ \\
3 & 1,744 & 146.61 & 728.87 \\
4 & 4,729 & 68.10 & 292.67 \\
5 & 8,553 & 29.21 & 162.00 \\
6 & 13,508 & 15.77 & 81.70 \\
7 & 16,552 & 9.32 & 55.01 \\
8 & 16,593 & 5.70 & 27.02 \\
9 & 15,231 & 3.92 & 20.85 \\
10 & 10,616 & 3.05 & 14.39 \\
11 & 6,264 & 2.38 & 10.46 \\
12 & 3,684 & 2.01 & 8.88 \\
13 & 1,722 & 2.26 & 11.22 \\
14 & 757 & 2.49 & 10.88 \\
15 & 350 & 1.58 & 5.60 \\
16 & 129 & 0.88 & 1.73 \\
17 & 37 & 0.88 & 1.06 \\
18 & &
\end{tabular}

"Frequency within a corpus of $2,600,000$ words. 
into relative values (in percentages over the total number of words), things change substantially.

Figure $1 \mathrm{~B}$ shows the same values transformed into percentages over the total number of words in each length segment. Notice that now the distributions are quite different, and the probability of finding words with a neighbor (or with a neighbor with certain frequency characteristics) changes. It is among the shortest words that we have the most probability of finding words with one or more neighbors and words with neighbors of higher or lower frequency. In fact, $100 \%$ of the 2 -letter words, $99 \%$ of the 3 -letter words, and $97 \%$ of the 4-letter words have neigh- bors. Among words 7-10 letters long, these values range from $77 \%$ to $54 \%$.

The similarity between the distributions of the categories comprised by words with neighbors of higher frequency and those comprised by words with neighbors of lower frequency is striking. That is, neighbors of higher frequency than the target word are as likely to be found as neighbors of lower frequency in the different length segments. However, when we look for words with neighbors having the same frequency, the distribution changes. This change affects shorter words in particular. We believe that the reasons for the drop in the number of neighbors of
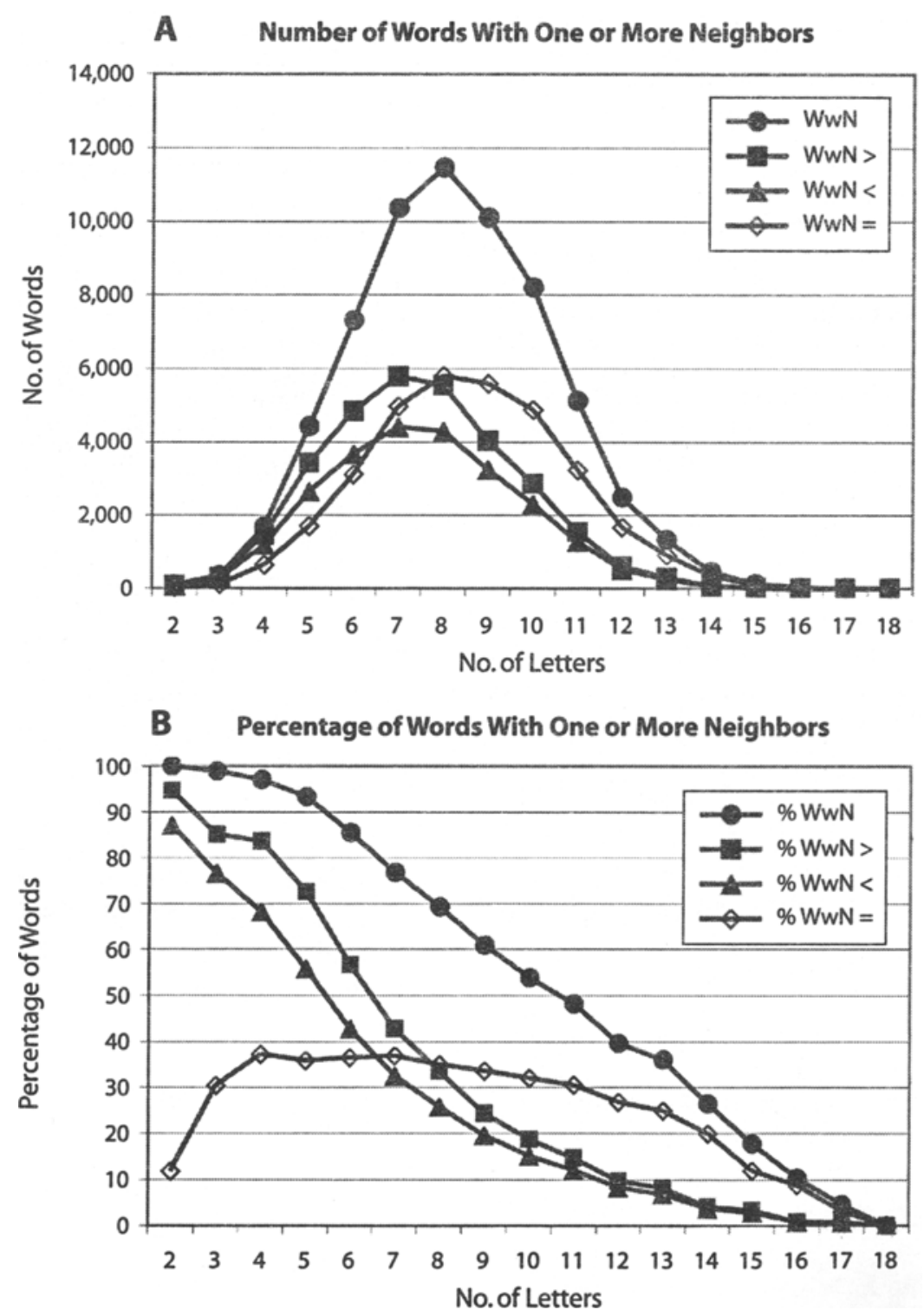

Figure 1. Relationship between word length and number of words with neighbors expressed in (A) absolute values (number of words) and (B) percentages. WwN, number of words with one or more neighbors; $W w N>$, number of words with one or more neighbors of higher frequency than the target word; WwN <, number of words with one or more neighbors of lower frequency than the target word; $W w N=$, number of words with one or more neighbors of equal frequency to the target word. 
equal frequency in the shortest word segments lie in the difficulty of finding words with the same frequency value in such small groups, and in the large degree of variability in the frequency values in such groups (see Table 1).

Neighborhood size and word length. When considering the average number of neighbors (neighborhood size) and the number of letters (word length) that each word has, we found an important correlation $(r=-.497)$ between these two variables. The negative sign of the correlation means that the longest words are those with the fewest neighbors and the shortest words have the largest neighborhoods (see Table 2). Taking into account that word length is limited, it seems logical to think that, the shorter the word, the greater the possibility of a letter's repeating in the same position. For 2-letter words, the average number of neighbors is around 11.7 , and this value progressively decreases as word length increases. Thus, for example, for 9-letter words this value is 1.1 - that is, on average they have only one neighbor.

The same phenomenon was described by Andrews (1997) in analyzing the 4- to 6-letter English words in CELEX. In this case, 7.2, 2.4, and 1.1 neighbors were found for words of 4,5 , and 6 letters, respectively. These values are slightly lower than ours, but, taking into account that the total number of words per length segment in Andrew's study is also lower $(1,895,2,895$, and 4,166, respectively), the proportions of neighbors are very similar despite the fact that the two databases are based on different languages and different populations.

It seems, therefore, that just as Andrews (1997) commented concerning adult English, there is also a strong relationship between word length and neighborhood size in the Spanish read by children during elementary school. In absolute terms, there are more words with one or more neighbors among words with 7-10 letters, but in relative terms (percentage of words with neighbors), the shortest words are the ones that reach the highest values. On the other hand, it is also the shortest words that have the highest absolute and cumulative frequencies in the neighborhood (see Tables 1 and 2) and that, on average, have the greatest numbers of neighbors. If we categorize the length variable in five intervals $(2-4,5-7,8-10,11-13$, and $>13)$ and enter it into Kruskal-Wallis nonparametric analysis (the variances are not homogeneous) as an independent variable, with number of neighbors as the dependent variable, we find that the differences are highly significant $(H=$ $19,894, p<.0001)$. In $2 \times 2$ comparisons of each of the four groups into which we stratified the variable by means of the Mann-Whitney $U$ test, all the tests are significant (all ps $<.0001$ ). The longest words have significantly fewer neighbors than the shortest words.

Neighborhood size and frequency. If we study the relationship between these two variables, we find that the correlation between the neighborhood size and the frequency of each word is practically null $(r=.081)$. However, if we establish four intervals in the frequency variable and calculate the number of neighbors for the group of words comprised in each of these intervals (see Figure 2), we find that the most frequent words have more neighbors than the least frequent words and that this relationship is statistically sig-
Table 2

Characteristics of the Neighborhood As a Function of Word Length Segment

\begin{tabular}{|c|c|c|c|c|}
\hline \multirow{2}{*}{$\begin{array}{l}\text { No. } \\
\text { Letters }\end{array}$} & \multicolumn{2}{|c|}{ No. NpW } & \multicolumn{2}{|c|}{ CFN } \\
\hline & $M$ & $S D$ & $M$ & $S D$ \\
\hline 2 & 11.66 & 4.75 & $88,881.96$ & $72,473.66$ \\
\hline 3 & 8.08 & 4.23 & $8,542.12$ & $15,323.20$ \\
\hline 4 & 8.69 & 5.84 & $1,587.77$ & $3,303.94$ \\
\hline 5 & 4.90 & 3.67 & 363.43 & 744.85 \\
\hline 6 & 2.81 & 2.32 & 98.58 & 299.77 \\
\hline 7 & 1.95 & 1.80 & 40.91 & 120.45 \\
\hline 8 & 1.46 & 1.47 & 22.78 & 94.63 \\
\hline 9 & 1.10 & 1.21 & 9.90 & 30.20 \\
\hline 10 & 0.89 & 1.08 & 6.78 & 21.69 \\
\hline 11 & 0.75 & 0.98 & 5.28 & 18.14 \\
\hline 12 & 0.57 & 0.84 & 3.00 & 7.94 \\
\hline 13 & 0.51 & 0.82 & 2.11 & 4.48 \\
\hline 14 & 0.33 & 0.63 & 1.77 & 5.37 \\
\hline 15 & 0.20 & 0.45 & 3.15 & 17.47 \\
\hline 16 & 0.14 & 0.49 & 0.82 & 0.79 \\
\hline 17 & 0.05 & 0.21 & 0.51 & 0.49 \\
\hline 18 & 0.00 & 0.00 & 0.00 & 0.00 \\
\hline
\end{tabular}

Note- NpW, neighbors per word; CFN, cumulative frequency of neighbors.

nificant in the Kruskal-Wallis analysis $(H=5,026, p<$ $.0001)$. The significance of this relationship is maintained in the $2 \times 2$ comparisons in each of the categories of the variable. Likewise, stepwise regression analysis was carried out taking neighborhood size as the dependent variable and word length and frequency as independent variables. The first variable to enter is length, which explains $24.7 \%$ of the variance. The variable frequency also enters into the analysis, although it explains only an additional $0.3 \%$ of the variance of the neighborhood size variable.

The reason for this somewhat fragile relationship between neighborhood size and frequency is less evident than the reason for the relationship between neighborhood size and length. One possible explanation could be that the most frequent words use frequent letters, which would increase the probability that the latter are repeated in similar positions. To verify this, we calculated the frequency of the bigrams that make up the words in our reference dictionary (Martínez $\&$ Garcia, 2004). This allowed us to calculate the type frequency of each pair of bigrams (successive letters), which,

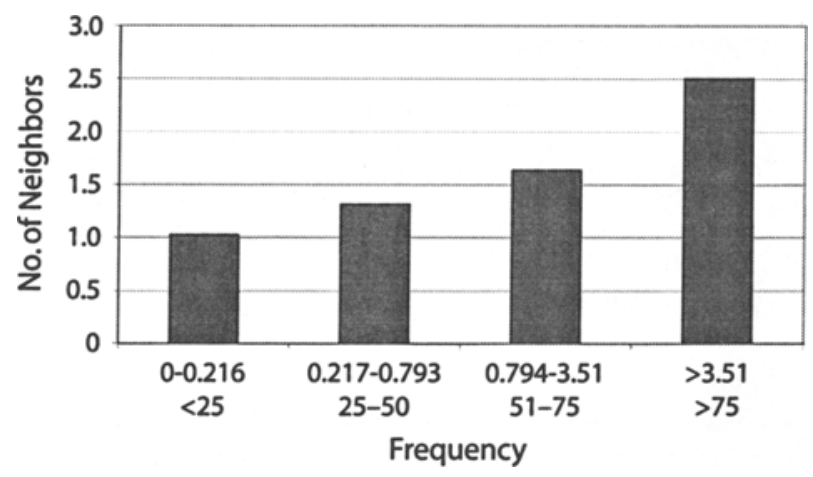

Figure 2. Relationship between neighborhood size and word frequency, grouped into four intervals of percentiles $(<25,25-50$, 50-75, and $>75$ ). 
as is known, reflects the number of words having this pair of letters in the same order. Since this analysis would have to be repeated in each group of words of a given length, we decided not to consider this variable and to calculate the frequency of the bigrams independently of word length. If we also calculate the mean frequency of the words that share those two letters, we will be able to estimate whether the bigrams most used by the different words correspond to those of the most frequent words. The correlation between these two variables (type frequency of the bigrams and mean of the frequency of those words) is virtually nonexistent $(0.00)$. Only when we eliminate the bigrams whose token frequencies are in the highest $10 \%$ frequency segment does a certain correlation $(r=.25, p<.0001)$ appear. The relationship between the frequency of the bigrams and that of the words seems to be true only for words of a certain frequency. This is probably the reason for the fragility of the results found in the relationship of these two variables.

\section{CONCLUSIONS}

It can be pointed out that there is a solid relationship between neighborhood size and word length. The likelihood that a word will have a neighbor clearly depends on its length. More specifically, in absolute terms, it is among the words with 7-10 letters that there is the greatest likelihood of finding more words with neighbors, but in relative terms (proportion of words with neighbors), the shortest words are the most likely to have neighbors. This is also true of the probability of having a neighbor of higher or lower frequency. Likewise, we have found the existence of a relationship - also significant, although less solid-between word frequency and neighborhood size. This relationship is more fragile and may be true only for certain frequency segments.

Although it is very likely that these very relationships will be maintained in analyses with neighbor databases for the adult population, it must be remembered that our conclusions are limited to a database of neighbors obtained from a dictionary based on texts read by children during elementary education. In any case, it seems reasonable to keep in mind that the distribution of the neighborhood over different length segments and different word frequencies is a key variable to consider in the selection of stimuli in the different research studies on neighbors and in the interpretation of their results.

\section{AUTHOR NOTE}

This work was financed by Grant PON2/04 of the Ministry of Education and Culture of the Regional Government of Castile and León, Spain. Correspondence concerning this article should be addressed to J. A. Martínez Martín, Calle Companía 5, 37002 Salamanca, Spain (e-mail: jmartinezma@upsa.es).

\section{REFERENCES}

AlAMEDA, J. R. (1996). Incidencia de la vecindad léxica ortográfica en el reconocimiento visual de palabras. Unpublished doctoral thesis, Universidad de Oviedo, Oviedo, Spain.

Alameda, J. R., \& Cuetos, F. (1995). Diccionario de frecuencias de las unidades lingüisticas del castellano [Dictionary of frequencies of linguistic units of Spanish]. Oviedo, Spain: Universidad de Oviedo, Servicio de Publicaciones.

AlAMEDA, J. R., \& Cuetos, F. (1996). Índices de frecuencia y vecindad ortográfica para un corpus de palabras de cuatro letras. Revista Electrónica de Metodologia Aplicada, 1, 10-29. Available at www.psico .uniovi.es/REMA.

Alameda, J. R., \& Cuetos, F. (2001). Indices de frecuencia y vecindad para palabras de cinco letras. Revista Electrónica de Metodologia Aplicada, 6, 1-62. Available at www.psico.uniovi.es/REMA.

ANDREws, S. (1997). The effect of orthographic similarity on lexical retrieval: Resolving neighborhood conflicts. Psychonomic Bulletin \& Review, 4, 439-461.

BaAyen, R. H., Piepengrock, R., \& Gulikers, L. (1995). The CELEX Lexical Database (CD-ROM). Philadelphia: University of Pennsylvania, Linguistic Data Consortium.

Balota, D. A., Yap, M. J., Cortese, M. J., Hutchison, K. A., KessLER, B., LOFTIS, B., ET AL. (2007). The English Lexicon Project Behavior Research Methods, 39, 445-459.

BarCa, L., Burani, C., \& Arpuino, L. S. (2002). Word naming times and psycholinguistic norms for Italian nouns. Behavior Research Methods, Instruments, \& Computers, 34, 424-434.

Buchanan, L., \& WestbURY, C. (2000). Wordmine database: Probabilistic values for all four to seven letter words in the English Language. [No longer available at www.wordmine.org; see www.wordmine2.org.]

BURANI, C., BARCA, L. \& ARDUINo, L. S. (2001). Una base di dati sui valori di età di acquisizione, frequenza, familiarità, immaginabilità, concretezza, e altre variabili lessicali e sublessicali per 626 nomi dell'italiano. Giornale Italiano di Psicologia, 4, 839-854.

Carreiras, M., Perrea, M., \& Grainger, J. (1997). Effects of the orthographic neighborhood in visual word recognition: Cross-task comparisons. Journal of Experimental Psychology: Learning, Memory, \& Cognition, 23, 857-871.

Coltheart, M. (1981). The MRC Psycholinguistic Database. Quarterly Journal of Experimental Psychology, 33A, 497-505.

Coltheart, M., DavelaAR, E., Jonasson, J. T., \& Besner, D. (1977). Access to the internal lexicon. In S. Dornic (Ed.), Attention and performance VI (pp. 535-555). Hillsdale, NJ: Erlbaum.

DAvis, C. J. (2005). N-Watch: A program for deriving neighborhood size and other psycholinguistic statistics. Behavior Research Methods, 37, 65-70.

DAvis, C. J., \& PereA, M. (2005). BuscaPalabras: A program for deriving orthographic and phonological neighborhood statistics and other psycholinguistic indices in Spanish. Behavior Research Methods, 37, 665-671.

Forster, K. (1976). Accessing the mental lexicon. In R. J. Wales \& E. Walker (Eds.), New approaches to language mechanisms (pp. 257-287). Amsterdam: North-Holland.

GRAINGER, J., \& SEgUI, J. (1990). Neighborhood frequency effects in visual word recognition: A comparison of lexical decision and masked identification latencies. Perception \& Psychophysics, 47, 191-198.

KuČERa, H., \& Francis, W. (1967). Computational analysis of presentday American English. Providence, RI: Brown University Press.

LAMBERT, E., \& ChESNET, D. (2001). NOVLEX: Une base de données lexicales pour les élèves de primaire. L'Année Psychologique, 101 , 277-288. Available at www.mshs. univ-poitiers.ff/ressources/novlex/.

LÉté, B., Sprenger-Charolles, L., \& ColE, P. (2004). MANULEX: A grade-level lexical database from French elementary school readers. Behavior Research Methods, Instruments, \& Computers, 36, 156-166.

MarTínez, J. A., \& Garcí, M. E. (2004). Diccionario de frecuencias del castellano escrito en niños de 6 a 12 años. Salamanca: Universidad Pontificia de Salamanca, Servicio de Publicaciones.

Martínez, J. A., \& Garcfi, M. E. (2007, August). Are frequency dictionaries specific for children necessary? Comparative study of a child and adult lexical frequency dictionaries. Paper presented at the 12th Biennial EARLI Conference, Budapest.

Masterson, J., Stuart, M., Dixon, M., Lovejoy, D., \& Lovejoy, S. (2003). Children's Printed Word Database. Available at www.essex. ac.uk/psychology/cpwd.

McClelland, J. L., \& RumelharT, D. E. (1981). An interactive activation model of context effects in letter perception: $P$ art 1 . An account of basic findings. Psychological Review, 88, 375-407.

MEDLER, D. A., \& BINDER, J. R. (2005). MCWord: An on-line ortho- 
graphic database of the English language. Available at www.neuro .mcw.edu/mcword.

PEREA, M. (1993). Una base de palabras de cuatro letras: f́ndices de frecuencia, familiaridad y vecindad ortográfica. Psicológica, 14, 307-317.

Perea, M., Urkia, M., Davis, C. J., Agirre, A., Laseka, E., \& CarreiRAS, M. (2006). E-Hitz: A word frequency list and a program for deriving psycholinguistic statistics in an agglutinative language (Basque). Behavior Research Methods, 38, 610-615. Available at www.uv.es/ mperea/E-Hitz.zip.

Pérez, M. A., Alameda, J. R., \& Cuetos, F. (2003). Frecuencia, longitud y vecindad ortográfica de las palabras de 3 a 16 letras del Diccionario de la Lengua Española (RAE, 1992). Revista Electrónica de Metodología Aplicada, 8, 1-20.

Pérez, M. A., CAmpoy, G., \& Navalón, C. (2001). Índice de estudios normativos en idioma español. Revista Electrónica de Metodologia Aplicada, 6, 85-105.

Real ACAdemia Española de la Lengua (1998). Diccionario de la Lengua Española (Electronic Version 2.0). Madrid: Espasa Calpe.

SEARS, C. R., Hino, Y., \& LuPKER, S. J. (1995). Neighborhood size and neighborhood frequency effects in word recognition. Journal of Experimental Psychology: Human Perception \& Performance, 21, 876-900.

Sebastián-Gallés, N., Marti, M., Carreiras, M., \& Cuetos, F. (2000). LEXESP: Léxico informatizado del español. Barcelona: Universitat de Barcelona.

THORNDIKE, E., \& LORGE, I. (1944). The teacher's word book of 30,000 words. New York: Teacher's College Press.

\section{NOTES}

1. The fact that there are more age-specific words in our (child) dictionary than in the adult dictionary is, in our opinion, fundamentally due to the fact that the former was developed starting from a considerably langer corpus of words $(20,460,751$ vs. $2,000,000)$. Note that, although our previous lexical dictionary (Martinez \& Garcia, 2004) is based on a much larger corpus of words, there are still words specific to the adult population (concretely, $31.43 \%$ of the total number of words of this dictionary).

2. This percentage was calculated as a function of the number of books read by a larger sample of children that served as a reference. Specifically, all the compulsory texts for each child were digitized, together with the number of books read by the child, which was not to be lower than the mean minus $0.6 S D$ s or higher than the mean plus 0.7 SDs of the reference sample. This criterion meant that, for some children, not all the books they read were digitized, and some books had to be eliminated.

\section{ARCHIVED MATERIALS}

The following materials associated with this article may be accessed through the Psychonomic Society's Norms, Stimuli, and Data archive, www.psychonomic.org/archive.

To access these files, search the archive for this article using the journal name (Behavior Research Methods), the first author's name (Martínez Martin), and the publication year (2008).

FILE: MartinezMartin-BRM-2008.zip.

DESCRIPTION: The compressed archive file contains 2 files:

ONESC.xls: Information relating to the words read during each academic year by Spanish children in elementary school for words of length 2 to 18 letters. Information includes the word; word frequency; number of letters; number of neighbors; cumulative frequency of neighbors; number of neighbors of greater, equal or lesser frequency; and the number of neighbors as a function of the position of the divergent letter. ONESC.txt: The same information in a separate tab-delimited text file.

AUTHOR'S E-MAIL ADDRESS: jmartinezma@upsa.es

(Manuscript received March 28, 2007; revision accepted for publication June 8,2007 .) 